\title{
EXTERNAL FLEXURAL STRENGTHENING OF RC BEAMS USING BFRP GRIDS AND PCM
}

\author{
AHMED MONIER ${ }^{1}, \mathrm{XU}_{\mathrm{ZHE}^{2}}$, HUANG HUANG ${ }^{3}$ and WU ZHISHEN ${ }^{4}$ \\ ${ }^{1} \mathrm{PhD}$ Candidate, Dept. of Urban and Civil Engineering, Ibaraki University \\ (Hitachi 316-8511, Japan) \\ ${ }^{1}$ Assistant Lecturer, Dep. Of Civil Engineering, Aswan University \\ (Aswan 81542, Egypt) \\ E-mail: ahmed.monier@aswu.edu.eg \\ ${ }^{2} \mathrm{MSc}$ Candidate, Dept. of Urban and Civil Engineering, Ibaraki University \\ (Hitachi 316-8511, Japan) \\ E-mail: 15nm8221@vc.ibaraki.ac.jp \\ ${ }^{3}$ Dr. of Eng., Dept. of Urban and Civil Engineering, Ibaraki University \\ (Hitachi 316-8511, Japan) \\ E-mail: hhly9527@gmail.com \\ ${ }^{4}$ Member of JSCE, Dr. of Eng. Prof. Dept. of Urban and Civil Engineering, Ibaraki University \\ (Hitachi 316-8511, Japan) \\ Email: zhishen.wu.prof@vc.ibaraki.ac.jp
}

\begin{abstract}
External strengthening of Reinforcement Concrete (RC) structures using epoxy-bonded Fiber Reinforced Polymer (FRP) sheets has some negative aspects, such as interfacial debonding and poor resistance ability of epoxy resin for fire and ultraviolet (UV), in addition to the working environment restrictions. To overcome some of those negative aspects, FRP grid bonded with Polymer Cement Mortar (PCM) to strengthen RC structures is developed and proposed in this study. The main objective of this paper is to study the efficiency between Basalt FRP grids and PCM in the flexural strengthening of RC beams. A tensile test was first conducted to determine the static longitudinal tensile strength and maximum elongation properties of the different BFRP grids. Then, the well-known double shear test was conducted to determine the bond mechanism between BFRP grids and concrete. Finally, the flexural behavior of the RC beam externally strengthened with BFRP grids was investigated through a fourpoint bending test. The results showed the efficiency of using BFRP grids as external strengthening method, as well as the stress-strain relationship of RC beams cross-section shows the compatibility with flexural theory.
\end{abstract}

Key Words: RC beams, BFRP grids, Bond Mechanism, Flexural strengthening

\section{INTRODUCTION}

In Japan, the issue of strengthening the existing civil engineering infrastructures has received urgent attention after the Kobe Earthquake of 1995. External epoxy-bonded Fiber Reinforced Polymer (FRP) sheets to the concrete surface has proven to be an effective technique since 1980 s $^{1-4)}$.
However, those strengthening techniques are often unable to attain the full tensile strength of the FRP sheet, because of the undesirable debonding failures ${ }^{5)}$. In addition, using epoxy as a bonding agent has some negative aspects, such as the use of organic resins which create a hazardous working environment for the manual worker and have low permeability, diffusion tightness, poor thermal 
compatibility with concrete and sensitivity to moisture at application. Also, most of the epoxies are also sensitive to low temperatures at application and after being installed cannot normally withstand temperatures above $70^{\circ} \mathrm{C}^{6}$.

Using PCM as a bonding agent is good technique for creating a more environmentally friendly and sustainable strengthening system. PCM is more brittle and may be difficult to penetrate and bond FRP sheets to concrete surfaces, however these mortars are more suitable to bond FRP grid to concrete surface ${ }^{7)}$.

Few works have studied the efficiency of using FRP grids as an external strengthening material. Iwashita et al. ${ }^{8)}$ reported that Carbon FRP (CFRP) grids exhibited superior bonding capacity with concrete surface compared to CFRP sheets. Chen et al. ${ }^{9)}$ studied the behavior of RC beams strengthened in shear with FRP grids; the beams strengthened with FRP grids exhibited a higher number of cracks with significantly smaller crack widths compared to beams strengthened with FRP sheets.

External strengthening using BFRP grids bonded with PCM has been proposed in this study to overcome the previously negative aspects of epoxybonded FRP sheets.

\section{MECHANICAL PROPERTIES OF BFRP GRIDS}

A series of tensile tests were conducted to determine the mechanical properties of the BFRP grids used in this study. BFRP grids were manufactured from dry basalt fibers and vinyl ester resin. According to the manufacturer pamphlet, the nominal tensile strength and elastic modulus of the dry basalt fibers were $2200 \mathrm{MPa}$ and $85 \mathrm{GPa}$, respectively. The grids used in this study were manufactured in three different thicknesses: 3, 4 and $5 \mathrm{~mm}$. the average width of the longitudinal segments was $15 \mathrm{~mm}$ approximately, and the axial distance between two consecutives longitudinal or transverse segments was $50 \mathrm{~mm}$. The density of the grids was $400 \mathrm{~kg} / \mathrm{m}^{3}$.

The specimens were prepared and tested according to the described method in ASTM D7205/D7205M. ${ }^{10)}$. The tested specimens were cut from the longitudinal segments of the grids with enough projections of the intersection joints to enhance gripping. Glass plates were used as anchorage devices. The total length of the specimens was $600 \mathrm{~mm}$ with an anchorage length of $150 \mathrm{~mm}$ at each end. Epoxy resin was used to bond the specimens to the plates and left to harden for seven days before testing.

A universal testing machine was used to conduct the tensile tests with a loading rate of $3 \mathrm{~mm} / \mathrm{min}$. The strain was measured by means of a linear variable differential transducer (LVDT) extensometer with a 5-mm gauge length placed at the mid-span of the tested specimens.

Table 1 summarizes the mechanical properties of the three different BFRP grids used in this study. All test results show a typical elastic behavior until brittle failure occurred. All tested specimens ruptured from tension at the straight portion between the anchorage devices, that proved the efficiency of the anchorage system used, as shown in figure 1 . The results show, the maximum applied force increased by increasing the grids thickness, the maximum applied force of BG-H was $30 \%$ higher than that of BG-L, as shown in figure 2.

Table 1 Mechanical properties of BFRP grids

\begin{tabular}{|c|c|c|c|c|c|}
\hline ID & $\begin{array}{c}\text { Th. } \\
\mathrm{mm}\end{array}$ & $\begin{array}{c}\text { Load } \\
\mathrm{kN}\end{array}$ & $\begin{array}{c}\text { Strain } \\
\%\end{array}$ & $\begin{array}{c}\text { Stress } \\
\mathrm{MPa}\end{array}$ & $\begin{array}{c}\mathrm{E} \\
\mathrm{GPa}\end{array}$ \\
\hline BG-L & 3 & 20.50 & 2.62 & 455.6 & 17.4 \\
\hline BG -M & 4 & 24.60 & 2.52 & 410.0 & 16.3 \\
\hline BG-H & 5 & 28.70 & 2.49 & 382.7 & 15.4 \\
\hline
\end{tabular}

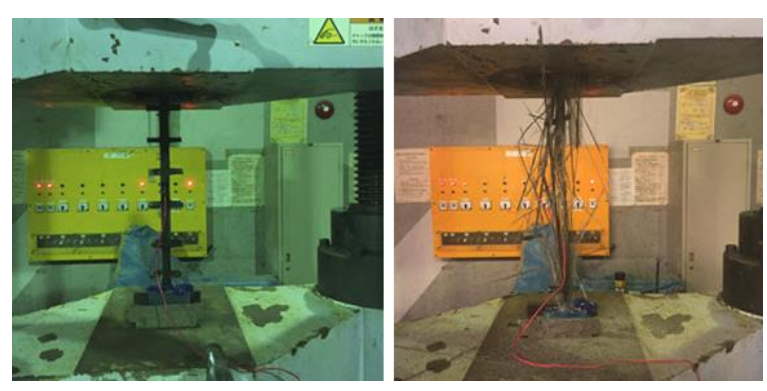

Fig.1 Test setup and failure mode of BFRP grid

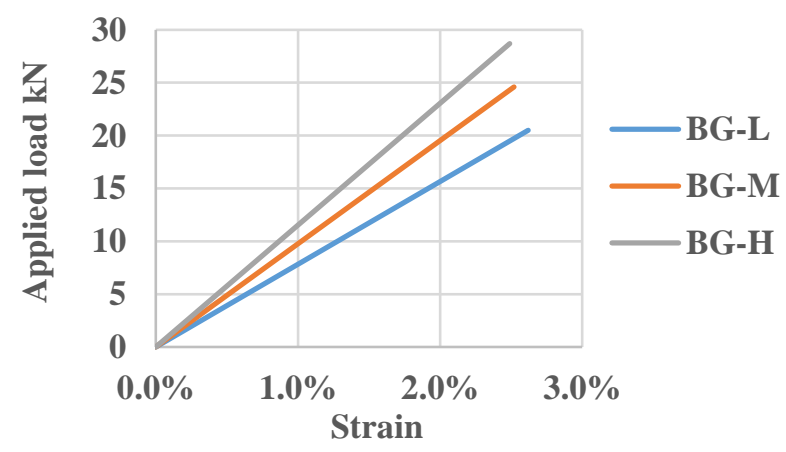

Fig.2 Load-strain curve of BFRP grids 


\section{BOND MECHANISM OF BFRP GRIDS}

The bond interfacial between the strengthened materials and the existing structures is a fundamental issue as it significantly influences the mechanical properties of the strengthened structures. So that, a direct bond test was conducted first to estimate the bond interfacial between BFRP grids and concrete surface, and compare with existing strengthening techniques.

\section{(1) Test setup}

Nakaba et al ${ }^{11)}$, showed different bond test types used to determine the bond mechanism between FRP and concrete surface. A double shear test was conducted in this study to obtain the bond characteristics between BFRP grids and concrete surface as shown in figure 3 .

A total of eighteen specimens were prepared and tested. Each specimen consisted of two concrete prisms separated by a wood plate and bonded with two segments of BFRP grids on opposite sides. A D20 $\mathrm{mm}$ steel rod was embedded in the center of each prism, so that the two prisms were connected only through the bonded BFRP grids. Each prism was $300 \mathrm{~mm}$ in length with a rectangular crosssection of $150 \mathrm{~mm}$ in side length. The measured compressive strength of the concrete was $30 \mathrm{MPa}$.

The double shear tests in this study were conducted using a universal testing machine with a loading rate of $1 \mathrm{~mm} / \mathrm{min}$. Two clip-strain gauges were attached to the opposing free surfaces of the prisms to determine the relative shear displacement. The strain distribution was obtained from six strain gauges set up on the mid longitudinal segment of the grid with intervals of $50 \mathrm{~mm}$.

Two parameters were studied; the thickness of the BFRP grids and the type of the bonding agents, three specimens for each test.

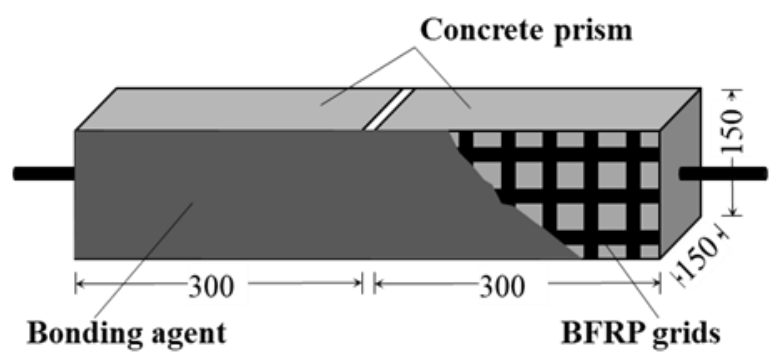

Fig.3 Double shear test
Previous studies have demonstrated that the maximum pull-out load initially increased with an increase in bond length until the effective bond length was reached. The maximum load remains constant if the bond length excesses this value. A debonding of FRP laminates from concrete surface occurs when the bond length is less than the effective bond length, while the failure mode is FRP rupture or concrete prism splitting if the bond length excesses that value.

A. Yehia et al ${ }^{12)}$, studied the bond mechanism of BFRP grids bonded with epoxy adhesive and recommended a bond length of $250 \mathrm{~mm}$. So, the bond length in this study is $300 \mathrm{~mm}$ to ensure the full composite action between BFRP grids and concrete surface.

Kamiharako et al ${ }^{13)}$, reported that FRP laminates width has no significant effect on the bond behavior when it is more than $10 \mathrm{~mm}$. The BFRP grid total width used in this study is $150 \mathrm{~mm}$.

\section{(2) Boning procedures}

Two bonding agents were studied in this study. First bonding agent was a PCM. The mortar was, one component, cement-based polymer reinforced and hydraulic hardening mortar. This mortar also contains a primer that purposed to enhance the bond interface between the concrete surface and the strengthened layer. This primer also prevents moist transportation from the wet mortar to the dry base concrete, leading to lesser crack formations and improved bonding ${ }^{14)}$. This mortar could be applied by a machine using the dry spraying method, as well as by trowel also. All specimens that bonded with PCM were handled using dry spraying method.

The mechanical properties of the PCM after 28days hardening were, $70 \mathrm{MPa}$ for compressive strength, $12 \mathrm{MPa}$ for flexural strength, and $23 \mathrm{GPa}$ for modulus of elasticity.

This mortar could also be used as a concrete repair product for the structural and non-structural repair of concrete structures (plain concrete and reinforced concrete); as a concrete repair product in the case of additional demands on structural support; as well as for establishing/restoring fire resistance. In addition, this mortar is a polymermodified, cementitious dry spray mortar (SPCC); high resistance to stress from frost/deicing salt; suitable for restoring fire resistance; system test as anode and repair mortar for cathodic protection; 
non-combustible, building material class A1; low dust formation; little rebound.

The main steps of external bonding using PCM were, first prepare the concrete substrate surface using high-pressure water jets (>800 bars), to open the pores and shrinkage holes, and remove the outer weak surface to expose a clean new surface, as well as water enhance the moisture condition of the existing concrete surface to minimize the water sucking out from the fresh mortar.

Secondly adjusting the cement - water ratio before spraying to the concrete surface. Then, the BFRP grids were set in the wood frame and the PCM was sprayed with a total thickness of $15 \mathrm{~mm}$, figure 4. Finally, the level and thickness of the strengthening layer were adjusted, and a thin plastic layer was placed over the mortar to avoid early shrinkage. All tested specimens that bonded with PCM were tested 28 days after spraying the PCM.

Second bonding agent in this study was epoxy putty. Specimens bonded with epoxy putty were handled by hand lay-up, the concrete surface was sandblasted to remove contamination and weak surface layers. Secondly a thin layer of a primer, a low viscosity material, was applied to form a chemical connection between the concrete surface and the relatively high viscosity epoxy putty. It was then left for two days to harden. After this, a uniform thin layer of the epoxy layer was applied with a putty knife on the primer layer. The BFRP grid was pressed onto the epoxy putty then the last layer of the epoxy putty was applied over the grid. The total thickness of the external layer in those specimens was $5 \mathrm{~mm}$. all specimens bonded with epoxy putty were tested 7 days after installation.

\section{(3) Failure modes}

The average results of the maximum load, relative displacement and failure mode obtained from the double shear test are given in table 2.

As expected, no debonding of BFRP grids from the concrete surfaces occurred in any specimen as the $300 \mathrm{~mm}$ bonded length exceeded the effective bond length. All specimens that bonded with PCM failed due to mortar failure (M.F) except for BG-H that had a premature failure. That premature failure happened due to the lack in the centricity of the 20D embedded steel rod in the concrete prism of the BGH-PCM specimens. So that the applied force acting on the concrete prism had an eccentricity leaded to this premature failure. Other specimens that bonded with epoxy putty failed due to concrete splitting (C.S) in the upper prism, as shown in figures 5-7.

Table 2 Double shear test results

\begin{tabular}{|l|c|c|c|}
\hline \multicolumn{1}{|c|}{ ID } & $\begin{array}{c}\text { Max } \\
\text { load } \\
\text { kN }\end{array}$ & $\begin{array}{c}\text { Max } \\
\text { disp. } \\
\text { mm }\end{array}$ & $\begin{array}{c}\text { Failure } \\
\text { mode }\end{array}$ \\
\hline BG-L-PCM & 66.98 & 3.28 & M.F. \\
\hline BG-M-PCM & 79.26 & 3.68 & M.F. \\
\hline BG-H-PCM & 53.32 & 2.37 & Pre. Failure \\
\hline BG-L-PUTTY & 65.31 & 3.44 & C.S. \\
\hline BG-M- PUTTY & 80.43 & 3.65 & C.S. \\
\hline BG-H- PUTTY & 81.60 & 3.31 & C.S. \\
\hline
\end{tabular}

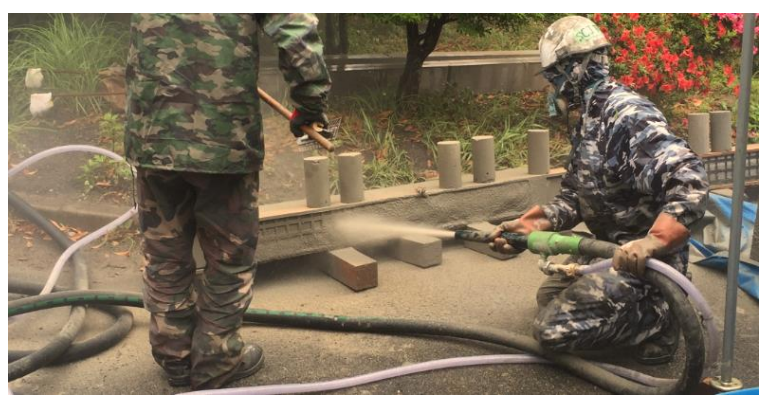

Fig.4 Dry Spray method of PCM

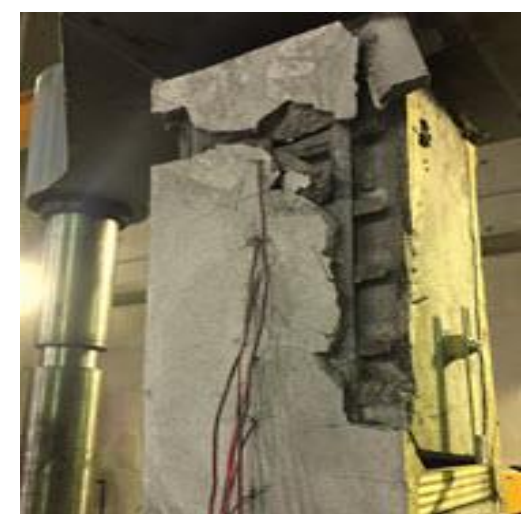

Fig.5 Mortar Failure

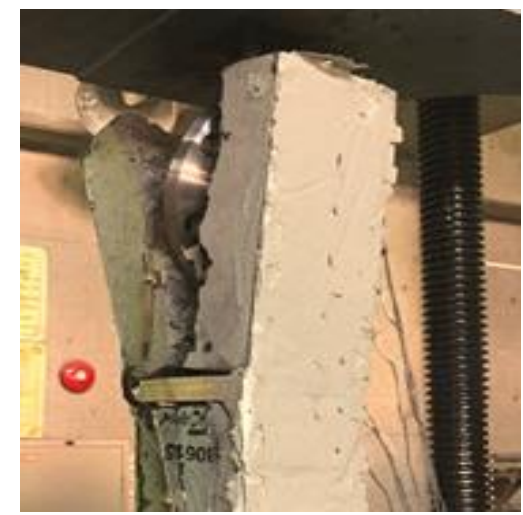

Fig.6 Concrete Splitting 


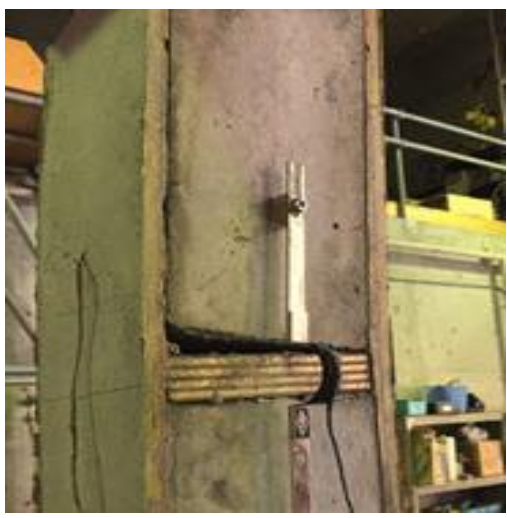

Fig.7 Premature Failure

\section{(4) Load-global displacement curve}

Figures 8 and 9 present the load-displacement curves for all tested specimens. The total displacement is the average of the data of the two clip-gauge attached to the opposite free surfaces of the prisms. The results clarify that increasing the BFRP grid thickness has a significant influence on increasing the maximum applied load, while has a minimal effect on the relative displacement.

For specimens bonded with PCM, the loaddisplacement curve consists of two main portions. In the first portion, the trend of the curve is a linear behavior from the start of loading until the first crack in the bonding agent PCM at a load of approximately $20 \mathrm{kN}$.

The linear elastic behavior could be associated with the linear elastic behavior of the mortar before the first crack. After a load of about $20 \mathrm{kN}$, the trend of the curve became nonlinear, which is called the second portion. In this portion, the interface between BFRP grid and PCM or between PCM and

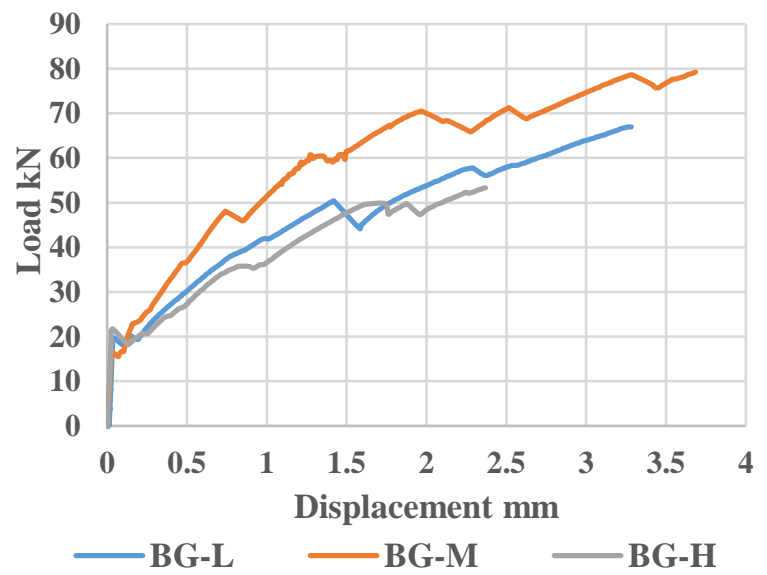

Fig. 8 Load-displacement curve for PCM specimens

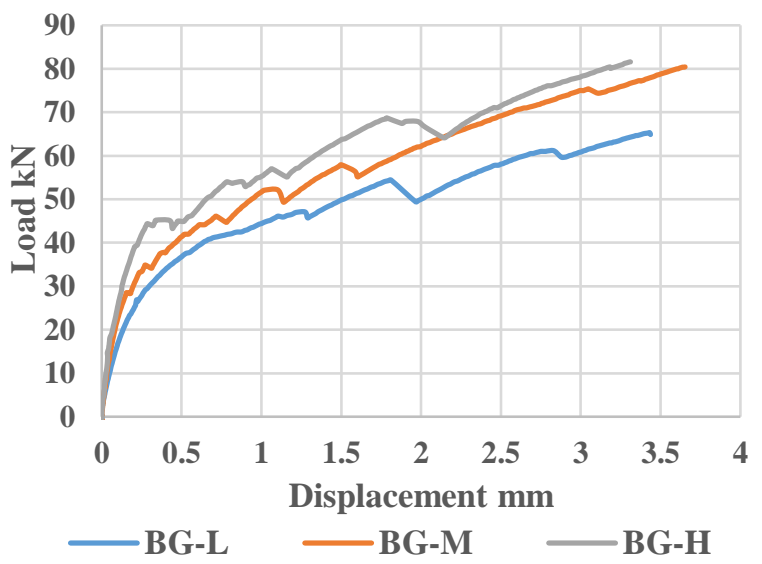

Fig.9 Load-displacement curve for Epoxy Putty specimens

concrete surface could experience some microdamages from increasing cracks width and numbers. The value of applied load increases until the total failure of the mortar. The specimens that bonded with epoxy putty failed due to concrete splitting in the upper prism. While the maximum applied load and relative displacement of the two bonding agents were similar, the PCM shows more efficiency with increasing the grid width.

\section{(5) Strain distribution}

The strain distribution versus the bond length of the specimen was obtained from the six strain gauges on the mid longitudinal segment of the grid. Figures 10-15 show the strain distribution of the different tested specimens at the max load before failure. The results show, the effective bond length for specimens bonded with PCM was $150 \mathrm{~mm}$, and for the specimens bonded with epoxy putty was $200 \mathrm{~mm}$. It's clear that the effective bond length decreased when PCM is used, showing its efficiency compared with putty as a bonding agent.



Fig.10 Strain distribution for BG-L-PCM 


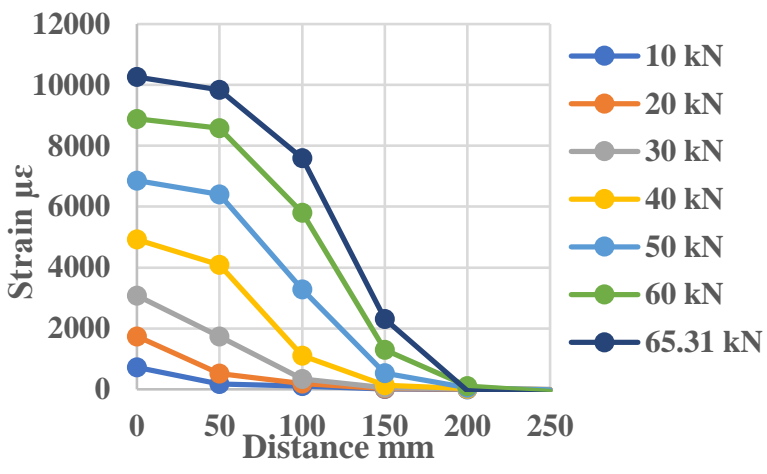

Fig.11 Strain distribution for BG-L-PUTTY

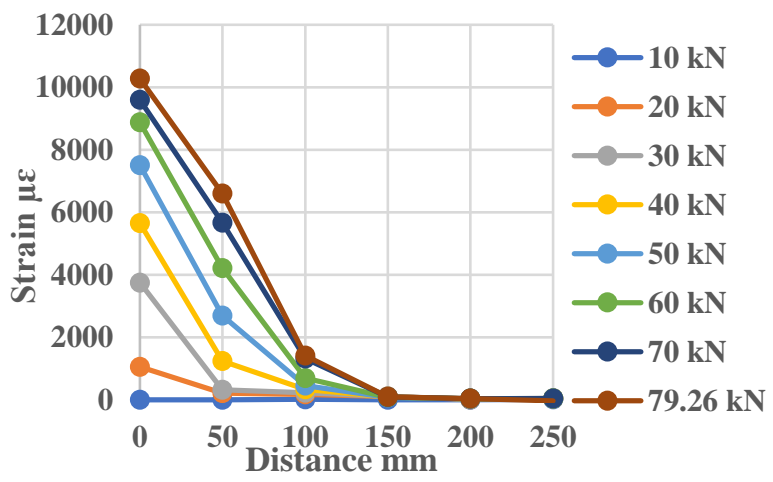

Fig.12 Strain distribution for BG-M-PCM

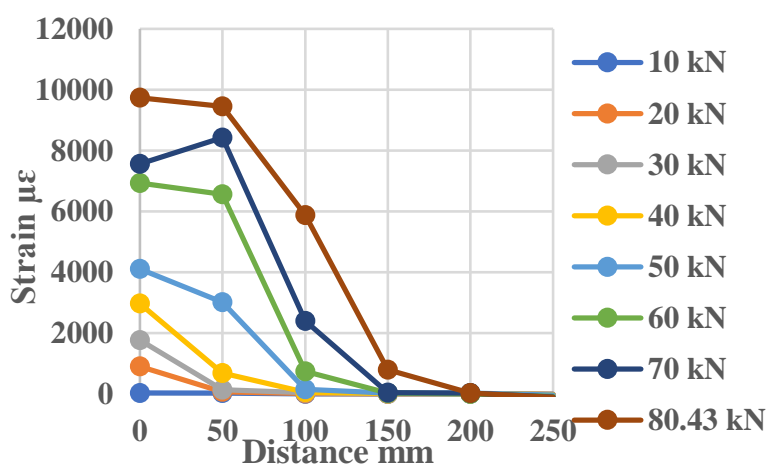

Fig.13 Strain distribution for BG-M-PUTTY

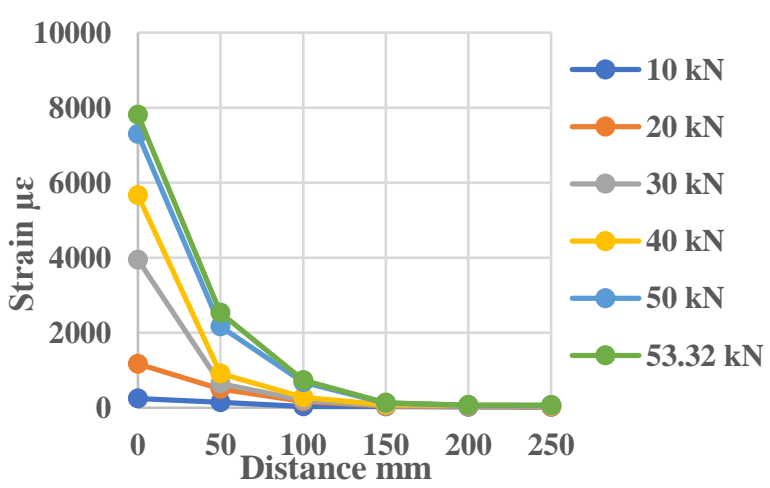

Fig.14 Strain distribution for BG-H-PCM

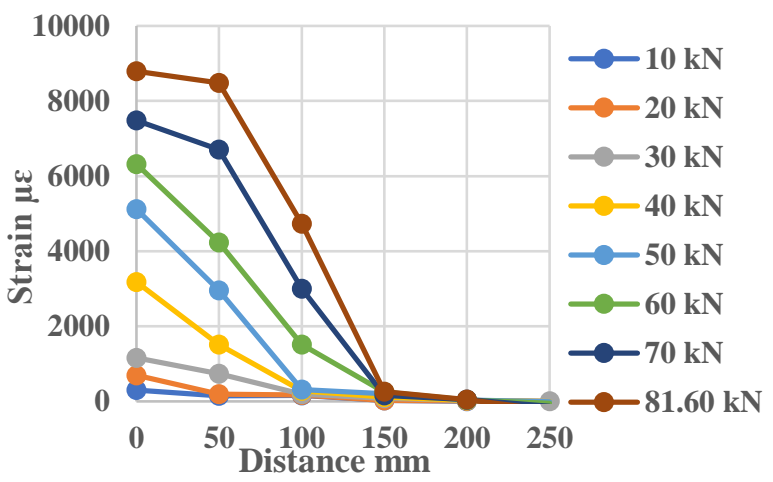

Fig.15 Strain distribution for BG-H-PUTTY

\section{(6) The interfacial fracture energy $\boldsymbol{G}_{\boldsymbol{f}}$}

$\mathrm{Wu}$ and Yin ${ }^{15)}$ defined the interfacial fracture energy $\left(G_{f}\right)$ as a key parameter to describe the shear strength of the bond interface of the FRP laminates and the concrete surface.

Täljsten ${ }^{16)}$ derived a simple equation to express the maximum pull-out load by the interfacial fracture energy and mechanical properties of FRP laminates as shown in the following equation (1).

$$
G_{f}=\frac{P_{\max }^{2}}{2 b_{f}^{2} E_{f} t_{f}}
$$

where,

$P_{\max }$ the maximum pull-out load,

$E_{f} \quad$ the strengthened layer's elasticity modulus,

$t_{f} \quad$ the strengthened layer's thickness, and;

$b_{f} \quad$ the strengthened layer's total width.

Table 3 summarized the calculated values of the interfacial fracture energy compared with previous studies done by Nakaba et al. ${ }^{11)}$ The interfacial fracture energy of BG-L, BG-M and BG-H bonded with PCM were $4.51,5.35$ and $2.14 \mathrm{~N} / \mathrm{mm}$, respectively. However, the maximum stiffness and relative interfacial fracture energy of FRP sheets tested by Nakaba et al. were $87.19 \mathrm{kN} / \mathrm{mm}$ and $1.50 \mathrm{~N} / \mathrm{mm}$, respectively with almost double concrete compressive strength of the prisms. From the results, BFRP grids have a high interfacial fracture energy compared with FRP sheets, this is an indicator of the bond efficiency of this technique as an external strengthening method. 
Table 3 The interfacial fracture energy $G_{f}$

\begin{tabular}{|c|c|c|c|c|c|c|c|c|}
\hline I.D. & $\begin{array}{c}\text { Concrete } \\
\text { Compressive } \\
\text { strength }\end{array}$ & $\begin{array}{c}\text { FRP } \\
\text { material }\end{array}$ & $\begin{array}{c}\text { FRP } \\
\text { type }\end{array}$ & $\begin{array}{c}\text { Bonding } \\
\text { Agent }\end{array}$ & $\begin{array}{c}\text { Max } \\
\text { Pull-out } \\
\text { load }\end{array}$ & $\begin{array}{c}\text { Fiber } \\
\text { width } \\
\boldsymbol{b}_{\boldsymbol{f}}\end{array}$ & $\begin{array}{c}\text { Stiffness } \\
\boldsymbol{E}_{\boldsymbol{f}} \cdot \boldsymbol{t}_{\boldsymbol{f}}\end{array}$ & $\boldsymbol{G}_{\boldsymbol{f}}$ \\
\hline BG-L-PCM & 30 & Basalt & Grid & PCM & 66.98 & 150 & 22.11 & 4.51 \\
\hline BG-M-PCM & 30 & Basalt & Grid & PCM & 79.29 & 150 & 26.10 & 5.35 \\
\hline BG-H-PCM & 30 & Basalt & Grid & PCM & 53.32 & 150 & 29.56 & 2.14 \\
\hline BG-L-PUTTY & 30 & Basalt & Grid & PUTTY & 65.31 & 150 & 23.77 & 3.99 \\
\hline BG-M-PUTTY & 30 & Basalt & Grid & PUTTY & 80.43 & 150 & 27.35 & 5.26 \\
\hline BG-H-PUTTY & 30 & Basalt & Grid & PUTTY & 81.60 & 150 & 30.35 & 4.88 \\
\hline C5-ARF & 57.6 & Aramid & sheets & Epoxy & 11.79 & 50 & 24.04 & 1.16 \\
\hline C5-HCF & 57.6 & Carbon & sheets & Epoxy & 21.60 & 50 & 70.14 & 1.33 \\
\hline C5-SCF & 57.6 & Carbon & sheets & Epoxy & 16.35 & 50 & 43.60 & 1.23 \\
\hline C5-SCFH & 57.6 & Carbon & sheets & Epoxy & 25.63 & 50 & 87.19 & 1.51 \\
\hline C5-SCFL & 57.6 & Carbon & sheets & Epoxy & 11.48 & 50 & 21.80 & 1.21 \\
\hline M5-ARF & 50.9 & Aramid & sheets & Epoxy & 12.43 & 50 & 24.04 & 1.29 \\
\hline M5-HCF & 50.9 & Carbon & sheets & Epoxy & 16.37 & 50 & 70.14 & 0.76 \\
\hline M5-SCF & 50.9 & Carbon & sheets & Epoxy & 15.70 & 50 & 43.60 & 1.13 \\
\hline M5-SCFH & 50.9 & Carbon & sheets & Epoxy & 22.29 & 50 & 87.19 & 1.14 \\
\hline M5-SCFL & 50.9 & Carbon & sheets & Epoxy & 9.35 & 50 & 21.80 & 0.80 \\
\hline C2-SCF & 23.8 & Carbon & sheets & Epoxy & 15.71 & 50 & 43.60 & 1.13 \\
\hline
\end{tabular}

\section{FLEXURAL STRENGTHENING OF RC BEAM}

A total of seven simply supported rectangular RC beams were constructed and tested to study the flexural strengthening efficiency of using BFRP grids. One beam was a control beam, while the other six beams were strengthened with BFRP grids. Three beams bonded with PCM, while the remaining three beams bonded with epoxy putty. The bond procedures were same as in double-shear test. All beams were tested in a four-point bending test under a static load.

\section{(1) Test setup}

The basic beam geometry has a height of $300 \mathrm{~mm}$, a width of $150 \mathrm{~mm}$, and a span of $1800 \mathrm{~mm}$ with a clear span $1600 \mathrm{~mm}$. The tensile reinforcement bars consisted of two D13 bars, and compression bars are two D6 bars. Shear reinforcement consisted of double-legged rectangular steel stirrups with a nominal diameter of $10 \mathrm{~mm}$, as shown in figure 16 . The yield stress of the longitudinal reinforcement was $440 \mathrm{MPa}$, and modulus of elasticity $200 \mathrm{GPa}$. Ready-mixed concrete was used with a specified compressive strength of $30 \mathrm{MPa}$. All beams were tested until failure using a $500 \mathrm{kN}$ capacity servocontrolled hydraulic actuator.



Fig.16 Details of the strengthened beam

Three LVDTs were used to measure the deflection at mid- span and at both ends of the bottom surface of the beam. The data was automatically collected using a data logger device (TDS-102). The location of cracks and their propagation was marked on the concrete surface at load increments of $10 \mathrm{kN}$ until the tensile reinforced bars yielding. Six strain gauges were installed on the side of the beam to measure the strain distribution of the cross-section of the beam. A strain gauge on the mid span of each steel bar and the longitudinal ribs of the grids was installed to measure the strain during the loading. The results of all tested beams are summarized in table 4 .

\section{(2) Failure mode}

The control beam exhibited the ideal plastic behavior after steel yielding and the failure mode was concrete compressive crushing by exceeding the ultimate compressive strain in the concrete 
compressive zone. Intermediate crack induced interfacial debonding (IC debonding) failure mode was observed in all strengthened beams.

IC debonding initiated at the flexural crack at the mid-span and then propagated towards the end of the external strengthening layer. Debonding failure involves a loss of the composite action between the beam and the strengthening layer.

The number of cracks increased while its width decreased by increasing the thickness of the BFRP grids, this behavior proves that using BFRP grids enhances the stress distribution along the beam length. Figures 17-23 show the failure mode of the seven tested beams.

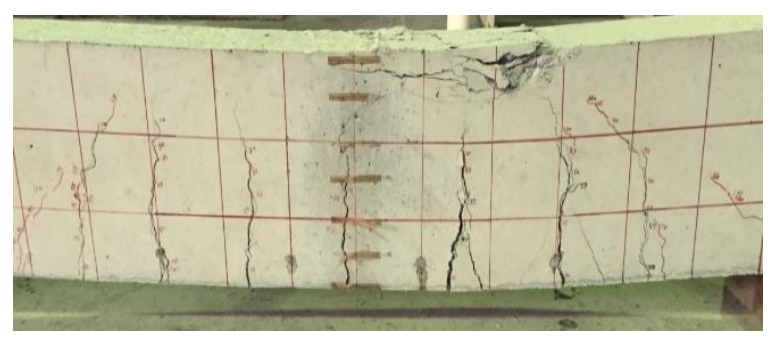

Fig.17 Failure mode of beam B0

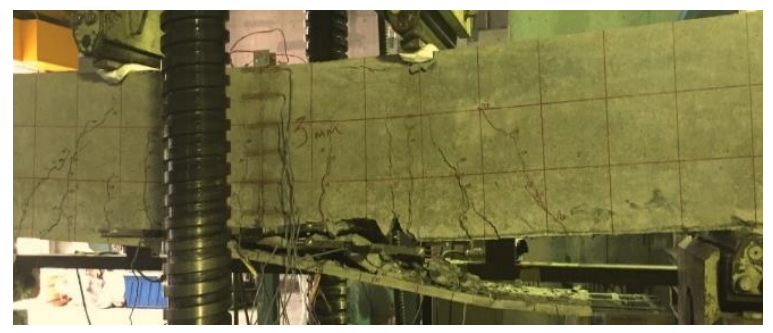

Fig.18 Failure mode of beam BG-L-PCM

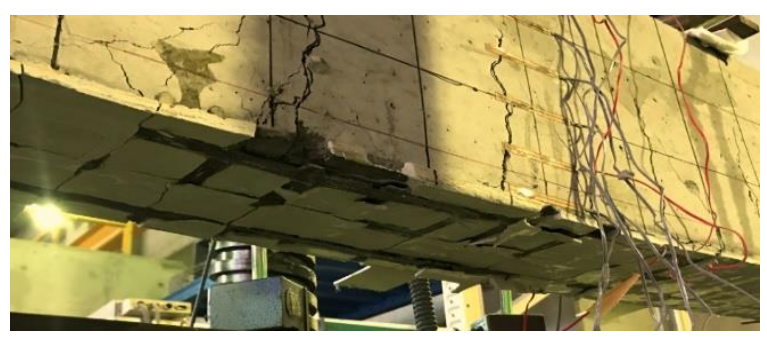

Fig.19 Failure mode of beam BG-L-PUTTY

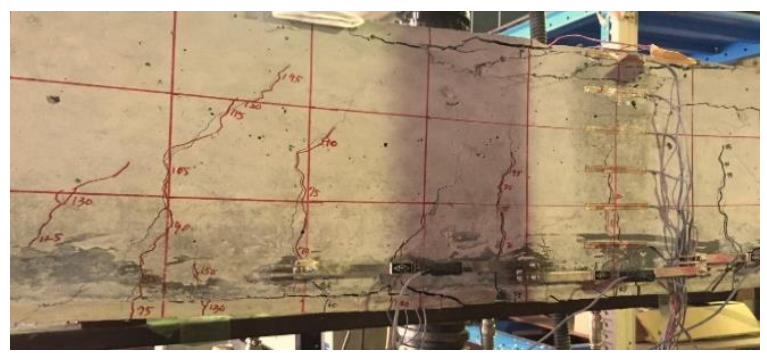

Fig.20 Failure mode of beam BG-M-PCM
Table 4 Flexural test results

\begin{tabular}{|c|c|c|c|c|}
\hline Beam & $\begin{array}{c}\text { Crack } \\
\text { Load } \\
\text { kN }\end{array}$ & $\begin{array}{c}\text { Yield } \\
\text { Load } \\
\mathrm{kN}\end{array}$ & $\begin{array}{l}\text { Ult. } \\
\text { Load } \\
\text { kN }\end{array}$ & $\begin{array}{c}\text { Max } \\
\text { Defl. } \\
\text { mm }\end{array}$ \\
\hline B0 & 32.12 & 120.3 & 139.6 & 39.15 \\
\hline BG-L-PCM & 45.70 & 159.2 & 223.9 & 22.00 \\
\hline BG-L-PUTTY & 37.85 & 148.5 & 221.7 & 20.71 \\
\hline BG-M-PCM & 45.72 & 160.2 & 228.4 & 18.48 \\
\hline BG-M-PUTTY & 37.96 & 150.2 & 229.5 & 20.86 \\
\hline BG-H & 46.36 & 16 & 219.5 & 13.85 \\
\hline BG-H-PUTTY & 39.17 & 154.2 & 206.0 & 15.01 \\
\hline
\end{tabular}

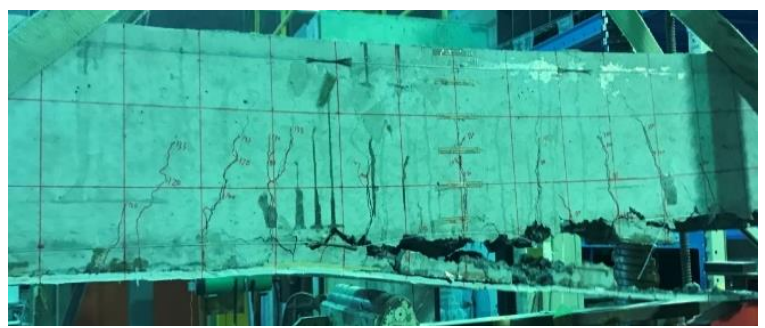

Fig.21 Failure mode of beam BG-M-PUTTY

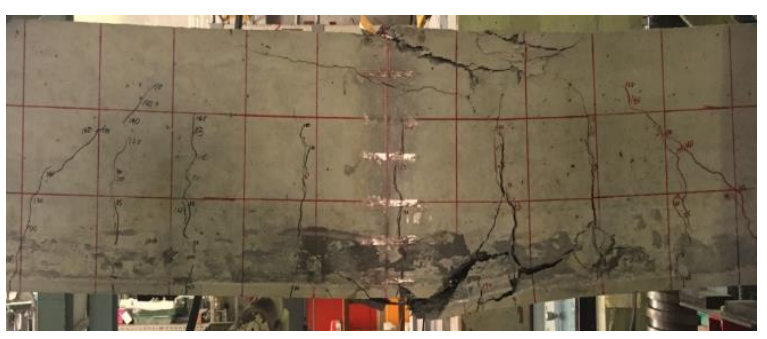

Fig.22 Failure mode of beam BG-H-PCM

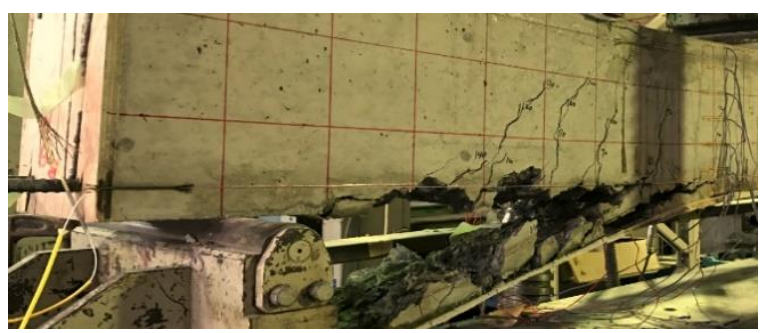

Fig.23 Failure mode of beam BG-H-PUTTY

\section{(3) Load-deflection relationship}

Figure 24 shows the load deflection curve of all tested strengthened beams bonded with PCM. The flexural behavior of all tested beams had three main stages. First stage is a non-cracked stage, from initial loading until the initiation of the first crack. The first crack and relative cracking load was determined by visual inspection of the beam during loading. The behavior of the beams in this stage was characteristic of linear-elastic behavior. The cracking load of the strengthened beams bonded with PCM and putty was about $43.0 \%$, and $19.3 \%$ 
higher than the cracking load of the control beam, respectively. The increases in cracking load of strengthened beams bonded with PCM was almost double of the beams bonded that with putty. The increases in the cracking load was a result of the new geometry of the beam, the thickness and the mechanical properties of the external bonding layer.

After the concrete cracked, the beam reached the second stage, which is called the in-service stage. This stage is characterized by the geometry of the beam and the axial stiffness of the tensile reinforcement bars and external strengthening layer. From load-deflection curves, strengthened beams had a higher flexural stiffness compared to the control beam. Since the yield strain of the tensile reinforcement bars is about $10 \%$ of the ultimate failure strain of the grids, there was no FRP rupture in this stage.

The yield loads of the strengthened beams BG-LPCM, BG-M-PCM, and BG-H-PCM were 159.2, 160.2 , and $163.9 \mathrm{kN}$, respectively. While, the yield loads of the beams bonded with epoxy putty were $148.5,150.2$ and $154.2 \mathrm{kN}$, respectively.

After tensile bars yielded, the control beam B0 exhibited typical plastic behavior until the compressive concrete crushing, while the strengthened beams exhibited a hardening behavior due to existing of BFRP grids. The flexural stiffness of the strengthened beams decreased after steel yielding as the tensile stresses on reinforcement bars remained essentially constant.

On the other hand, the hardening stiffness of the strengthened beams increased by increasing the thickness of the BFRP grids. The hardening behavior improved the flexural capacity of the beams, while reducing the deflection of the beams.

The load-deflection behavior in the hardening stage was almost linear up to final failure.

The ultimate load of the strengthened beams BGL-PCM, BG-M-PCM, and BG-H-PCM was 223.9, 228.4 , and $219.5 \mathrm{kN}$, respectively. While, the ultimate load of the beams bonded with epoxy putty was $221.7,229.5$ and $206.0 \mathrm{kN}$, respectively.

From figures 25-27, the load-deflection curves show that using epoxy putty as a bonding agent has some limitations in the bond mechanism with increasing the fiber content comparing to PCM.

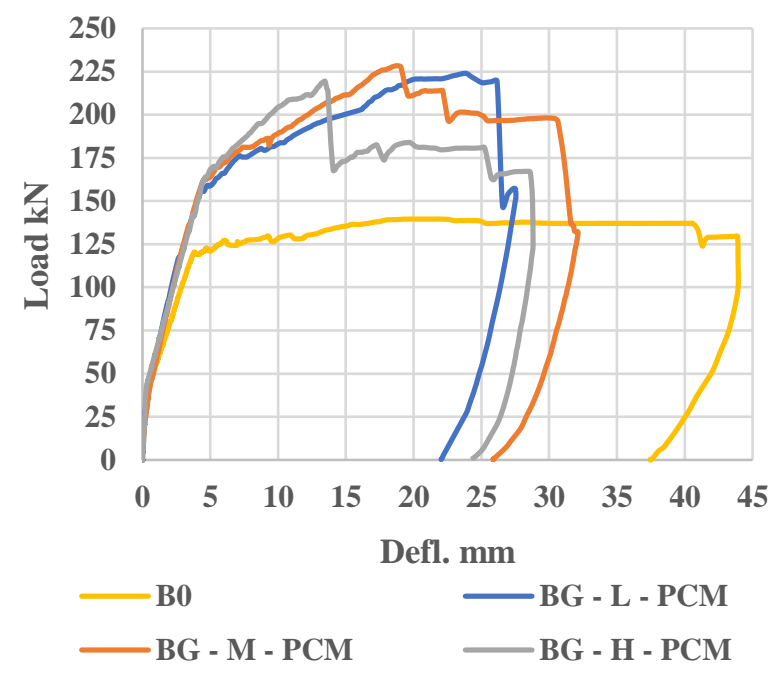

Fig.24 Load-deflection curve for strengthened beam with BFRP grids and PCM

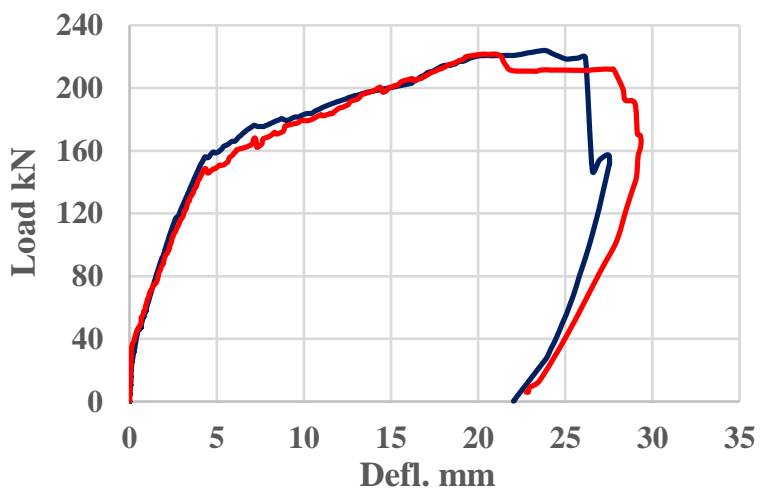

$\longrightarrow \mathrm{BG}$ - L - PCM $\longrightarrow \mathrm{BG}$ - L - PUTTY

Fig.25 Load-deflection curve for strengthened beam BG-L

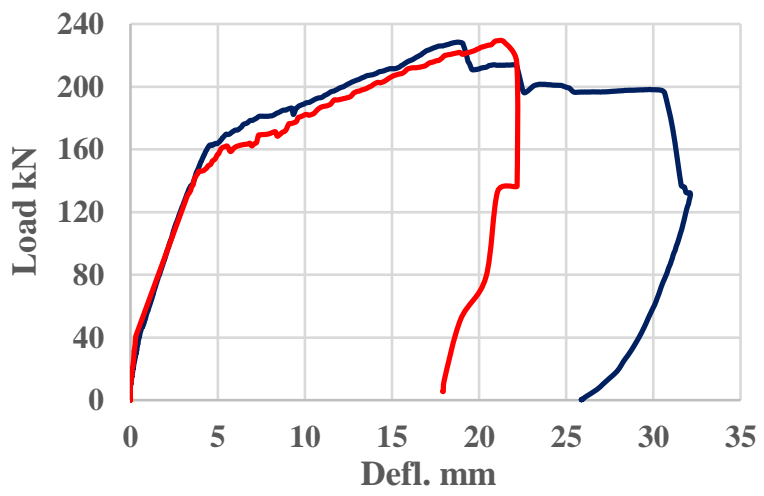

$\longrightarrow$ BG - M - PCM —BG - M - PUTTY

Fig.26 Load-deflection curve for strengthened beam BG-M 


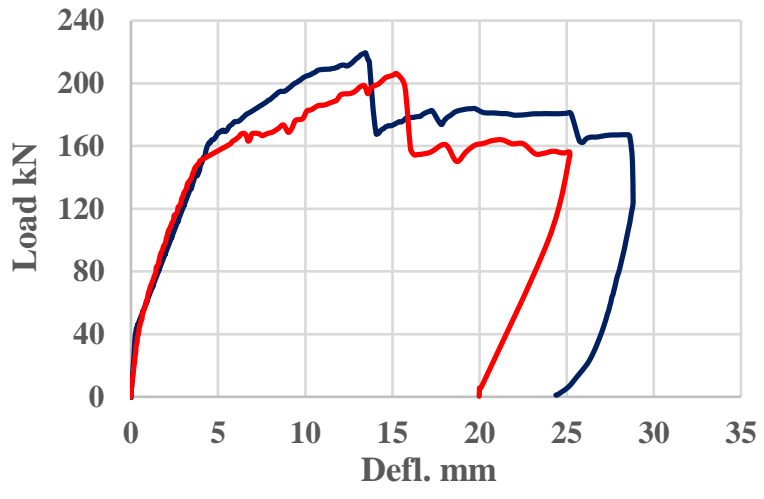

BG - H - PCM —BG - H - PUTTY

Fig.27 Load-deflection curve for strengthened beam BG-H

\section{(4) Design of the strengthened beams}

Figures 28-30 show the strain distribution along the cross-section at the mid-span of the beam. The distribution of that measured strains was nearly linear during the loading until failure. The visual inspection of the strengthened beams during loading shows that there is a good compatibility between RC beams and PCM, even after steel bar yielding. The strain distributions along the crosssection of the tested strengthened beams were proportional to the distance from the neutral axis of the beam, so that flexural theory could be apply to a strengthening design by this technique.

\section{CONCLUSIONS}

This study presented a series of experimental studies on the bond mechanism of BFRP grids to concrete surface and the flexural strengthening of RC beams.

a) The double shear tests showed the bond efficiency of using BFRP grid and PCM as an external strengthening material.

b) The interfacial fracture energy $G_{f}$ of the BFRP grids is higher than FRP sheets reported in the literature.

c) The ultimate load of strengthened beams with BFRP grids was enhanced by $47.60-63.65 \%$ in comparison to the reference beam.

d) The flexural capacity of strengthened RC beams with BFRP grids bonded with PCM could be estimated based on the flexural theory.

e) Epoxy putty showed some limitations in the bond mechanism with increasing the fiber content comparison to using PCM as a bonding agent.

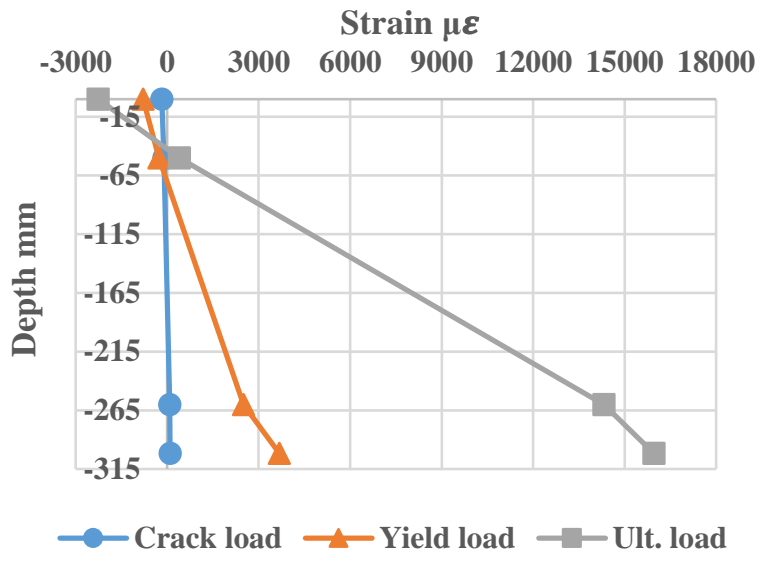

Fig.28 Strain distribution of BG-L-PCM

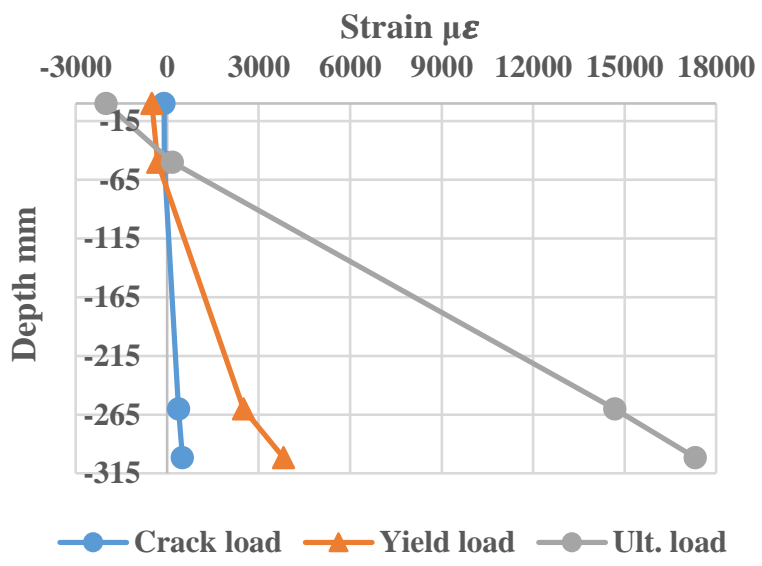

Fig.29 Strain distribution of BG-M-PCM

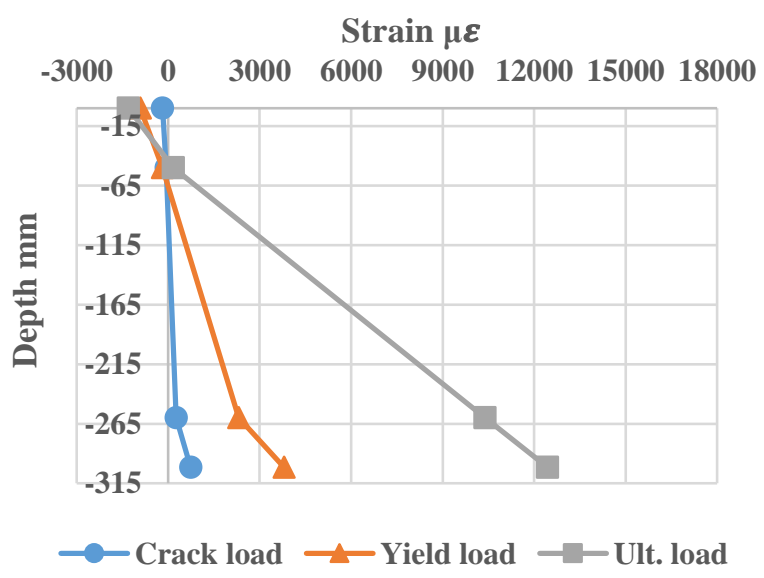

Fig.30 Strain distribution of BG-H-PCM

ACKNOWLEDGMENT: The authors acknowledge StoCretec Japan for providing and spraying PCM. 


\section{REFERENCES}

1) Meier, U.: Bridge repair with high performance composite materials, Material \& Technik, Vol. 4, pp. 125-128,1987 (in German).

2) Triantafillou, T. C. and Plevris, N: Strengthening of RC beams with epoxy-bonded fiber-composite materials. Materials and Structures, vol. 25, pp. 201-211, 1992.

3) Tepfers, R: Bond of FRP reinforcement in concrete: A state-of-the-art in preparation, ACI Special Publication, Vol. 180, pp. 493-504, 1998.

4) Fukuyama, H., and Sugano, S.: Japanese seismic rehabilitation of concrete building after the Hyogoken Nanbu earthquake, Cem. Concr. Compos., Vol. 22, pp. 59-79,2000.

5) Nageh M., Xin Wang, Zhishen Wu, and Yehia A: Basalt fiber reinforced polymer grids as an external reinforcement for reinforced concrete structures. Journal of Reinforced Plastics and Composites. Vol 34, Issue 19, pp.1615-1627, 2015.

6) Blanksvärd T.: Strengthening of concrete structures by the use of mineral-based composites, Doctoral Thesis, Lulea University of Technology, pp. 3.2009.

7) Täljsten, B., and Blanksvärd, T.: Mineral based bonding of carbon FRP to strengthen concrete structures. $J$. Compos. Constr., Vol. 11, Issue 2, pp 120-128,2007.

8) Iwashita $\mathrm{K}, \mathrm{Wu} \mathrm{Z}$ and Sakamoto K.: Investigating and upgrading anchorage performances of FRP grids bonded internally in concrete with underwater epoxy putty, JSCE Journal of materials, concrete structures and pavements, Vol.63, No.2, pp. 214-222, 2007.

9) Chen W, Chen X and Yi D.: The shear behavior of beams strengthened with FRP grid". CICE 2010 - the fifth international conference on FRP composites in civil engineering, Beijing, China, September, pp 772$775 ., 2010$

10) D7205/D7205M: A. Standard test method for tensile properties of fiber reinforced polymer matrix composite bars. ASTM International, West Conshohocken, PA 19428, 2011.

11) Nakaba Kasumassa, Kanakubo Toshiyuki, Furuta Tomoki, and Yoshizawa Hiroyuki: Bond behavior between fiber-reinforced polymer laminates and concrete. ACI Struct J, Vol 98, Issue 3, pp. 359-367,2001.

12) Ahmed Yehia, Xin Wang and Zhishen Wu: Flexural Behavior of RC Beams Strengthened with Basalt FRP Grids, 11th International Symposium on Fiber Reinforced Polymer for Reinforced Concrete Structures, ISBN 978972-8692-84-1, 2013.

13) Kamiharako, A., Shimomura, T., Maruyama, K. and Nishida, H.: Analysis of Bond and Debonding Behavior of Continuous Fiber Sheet Bonded on Concrete, Journal of Materials, Concrete Structures and Pavements, Japan Society of Civil Engineers, Vol. 634, pp. 197-208.,1999.

14) Xiong, G., Liu, J., Li, G., and Xie, H.: A way for improving interfacial transition zone between concrete substrate and repair materials., Cem. Concr. Res., Vol 32, Issue 12, pp.1877-1881, 2002.

15) Zhishen WU and Jun YIN: Numerical Analysis on Interfacial Fracture Mechanism of Externally FRPStrengthened Structural Members. J. Materials, Conc. Struct. Pavements, JSCE, No. Vol 704, Issue 55, pp. 257270, 2002.

16) Taljsten B.: Strengthening of concrete prisms using the plate bonding technique, International Journal of Fracture, Vol. 82, pp. 253-266, 1996.

(Received June 23, 2017) 